\title{
Mental health in UK Biobank: development, implementation and results from an online questionnaire completed by 157366 participants - RETRACTED
}

Katrina A. S. Davis, Jonathan R. I. Coleman, Mark Adams, Naomi Allen, Gerome Breen, Breda Cullen, Chris Dickens, Elaine Fox, Nick Graham, Jo Holliday, Louise M. Howard, Ann John, William Lee, Rose McCabe, Andrew McIntosh, Robert Pearsall, Daniel J. Smith, Cathie Sudlow, Joey Ward, Stan Zammit and Matthew Hotopf

\section{Copyright and usage}

(C) The Royal College of Psychiatrists 2019. This is an Open Access article, distributed under the terms of the Creative Commons Attribution-NonCommercial-NoDerivatives licence (http://creativecommons.org/licenses/by-nc-nd/4.0/), which permits non-commercial reuse, distribution, and reproduction in any medium, provided the original work is unaltered and is properly cited. The written permission of Cambridge University Press must be obtained for commercial re-use or in order to create a derivative work.

https://doi.org/10.1192/bjo.2018.12, Published online by Cambridge University Press, 03 April 2018

We, the Editors of BJPsych Open, have retracted the following article:

Davis et al, 'Mental health in UK Biobank: development, implementation and results from an online questionnaire completed by 157 366 participants', BJPsych Open, Volume 4, Issue 3, pp. 83-90 Retracted.

In January 2019, the authors of this paper voluntarily submitted a corrigendum to the publisher which acknowledged that a data analysis coding error for Alcohol Use Disorders Identification Test (AUDIT) resulted in decreased alcohol use disorders prevalence and a resultant decrease in total psychiatric disorder prevalence.

An investigation by the Senior Editorial Board revealed that whilst this was a relatively minor coding error, it had led to a major and important change in the findings noted in the abstract, results section and associated comorbidity tables.
To ensure research integrity, the board decided that retraction of the original article with subsequent resubmission of a corrected paper would be the best course of action.

No institutional investigation or sanctioning by the Journal is indicated.

All of the authors agree to the retraction.

We discuss more fully the issues and our response to them in an accompanying editorial (Kaufman et al., 2019).

Katrina A.S. Davis; Jonathan R.I. Coleman Mark Adams; Naomi Allen Gerome Breen; Breda Cullen Chris Dickens; Elaine Fox; Nick Graham; Jo Holliday; Louise M. Howard; Ann John; William Lee; Rose McCabe Andrew McIntosh; Robert Pearsall; Daniel J. Smith; Cathie Sudlow; Joey Ward; Stan Zammit; Matthew Hotopf

\section{References}

Davis KAS, Coleman JRI, Adams M, Allen N, Breen G, Cullen B, Dickens C, et al. Mental health in UK Biobank: development, implementation and results from an online questionnaire completed by 157366 participants. BJPsych Open 2018; 4(3): 83-90.

Kaufman KR, Malhi GS, Bhui KS. When a corrigendum is not sufficient. BJPsych Open 2019; 5. doi: 10.1192/bjo.2019.41 